\title{
Understanding community perceptions of aquaculture: lessons from Australia
}

\author{
Nicole A. Mazur · Allan L. Curtis
}

Received: 24 January 2008/ Accepted: 28 January 2008/Published online: 13 March 2008

(C) Springer Science+Business Media B.V. 2008

\begin{abstract}
Aquaculture is a growing and high-value industry that depends on access to and wise use of shared inland, coastal and marine resources. Varied stakeholders and communities are very interested in these public resources, and there has been conflict about how the aquaculture industry uses them. Prior to the research discussed in this article, there have been few large-scale studies of community perceptions of aquaculture. Our research drew upon an extensive literature review, stakeholder interviews and a survey mailed to the public in two regional case studies in Australia: the Eyre Peninsula in the state of South Australia and Port Phillip Bay in the state of Victoria. The data revealed some public support for aquaculture's socioeconomic benefits and strong interest in minimizing the risk of its environmental impacts. There were mixed opinions about the trustworthiness of governments' aquaculture decisions and actions. Some industry sectors attracted greater trust and lower perceived environmental risks. The importance and credibility of different information sources varied. There was strong support for improved dialogue among governments, the aquaculture industry and communities. Key differences between the regions included levels of awareness of and knowledge about aquaculture. Our research is consistent with literature on risk communication and perception that suggests that conflict and subsequent costs to industry and the community can be overcome or mitigated if government and industry understand, acknowledge and respond to community perceptions of the industry.
\end{abstract}

Keywords Aquaculture - Natural resource management - Risk perceptions · Social research $\cdot$ Sustainability

N. A. Mazur $(\square)$. A. L. Curtis Institute for Land, Water and Society, Charles Sturt University, P.O. Box 789, Albury, NSW 2640, Australia e-mail: nickimazur@grapevine.net.au

A. L. Curtis

e-mail: acurtis@csu.edu.au 


\section{Introduction}

Achieving ecologically sustainable development (ESD) is thought to be the overriding challenge for global aquaculture (FAO 2002). A key aspect of this challenge is to reconcile the range of opinions about aquaculture's economic, social and environmental benefits and costs. The industry is believed to provide critically important supplements to the declining supplies of seafood, which are being stretched by increasing demand and have important economic benefits for remote/rural regions (Varadi et al. 2001; FAO 2002; PMSEIC 2002; Katranidis et al. 2003). Conversely, there are concerns about aquaculture's current and future negative environmental impacts, particularly with marine fish farming (Black 2001; Naylor et al. 2001; Pauly et al. 2002). Impacts resulting from the siting and operations of aquaculture farms include the use of large inputs of wild fish for feed, habitat modification and/or loss, reduced water quality, escapes of diseases and/or exotic species, competition with and other negative effects on wild stocks and/or wildlife, and reduced amenity values (e.g. restricted access, reduced visual amenity, noise) (Productivity Commission 2004).

These differences of opinion about aquaculture's sustainability are essentially a subset of broader dialogues about natural resource management. People hold different values about the environment and their varied beliefs about appropriate human relationships with natural systems underpin debates about how best to develop and manage natural resources (Creighton et al. 1997; Dryzek 1997; Connelly and Knuth 2002). These varied perspectives, in turn, inform how people define what are the most important problems requiring attention. The process of framing problems in a particular way influences how they are understood by others, who will participate in solving such 'problems' and how, and what values will be favoured by the resulting actions and solutions (Harding 1998; Swaffield 1998; Clark et al. 2000). Typically, insufficient time and effort is devoted to appreciating the different ways that communities and officials perceive natural resource issues and of the need to build mutual understanding of those 'problems' (Bardwell 1991). Without this kind of information, the risk of failed project approvals, policy/procedural changes, substantial time delays, loss of resources, social conflict, and/or decreased public confidence and support increases considerably (Shindler et al. 2002a).

The debates about aquaculture, as well as competition for resource access, underpin aquaculture-related conflicts, which occur around the world (see Varadi et al. 2001; FAO 2002; Kaiser and Stead 2002; Fraser and Beeson 2003; MWGA 2003). This article reports on Australian research seeking to understand different views about aquaculture, as a first step in efforts to address some of the controversy and public conflict associated with the industry. The design of this research was informed by a review of literature examining attitudes to natural resource management (forest and ecosystem management in the USA and water use and allocation, coastal management, commercial fishing, and mining in Australia), perceptions of and attitudes to aquaculture (Australia, Canada, Europe and United States), and risk perceptions and communication (Mazur 2004). There are similarities and differences between aquaculture and other natural resource industries and between Australian and overseas aquaculture industries. However, natural resource management in Western nations with highly developed and integrated economies is characterised by a complex web of interests and trade offs between different sets of actors (Grimble and Wellard 1997). Our experience (Curtis et al. 2002) is that careful reflection using regional case studies is a valid and helpful approach to building knowledge, theory and improving practice.

There have been local, regional and national studies in Australia, Canada, Europe, Mexico and the United States examining perceptions of the industry's sustainability, how 
communities value the industry and appropriate institutional responses to the industry's challenges. One study in the United States and two in Australia suggested that parts of society view the industry's environmental sustainability favourably, although there was low awareness of some of the environmental issues challenging the industry (Blackstone 2001; Aslin and Byron 2003; Mazur et al. 2004a, b). Katranidis et al. (2003) found that acceptance of aquaculture activities was greater where socioeconomic benefits were perceived to be high and there was lower incidence of concerns about environmental pollution from the industry. Other work in Australia has suggested that aquaculture's social acceptability increases where its socioeconomic benefits (e.g. employment opportunities) can be clearly demonstrated and communities and stakeholders are kept well informed about the industry's environmental impacts and governments' regulatory and management processes (Clarke 1996; Carvalho 1998; Wilson 2001). Hugues-Dit-Ciles (2000) demonstrated that where the values and needs of local communities in Mexico were incorporated into aquaculture planning prior to development, the industry's social, economic and environmental sustainability could more easily be secured. Kaiser and Stead (2002) identified a range of uncertainties and perspectives affecting European coastal aquaculture. They and others have concluded that increased use of integrated (marine and coastal) planning, which features more open, transparent and participatory fora, is required to help the industry achieve its full potential (Donnan 2001; Varadi et al. 2001; FAO 2002; Stead et al. 2002; Fraser and Beeson 2003; Mazur et al. 2004a, b; Mazur et al. 2005).

One important aspect of the disputes about aquaculture management and planning that has been neglected is how people's varied perceptions of risk might inform their concerns about the industry. Today, risk tends to be defined more negatively than in terms of its possible benefits: the probability that a bad event will occur plus the undesirable consequence(s) of that event (Douglas 1992). Debates about the environmental costs of the aquaculture industry indicate that parts of the public may be attending more to the (current or potential) negative risks from the industry than they are being reassured by its benefits. In the broader literature on risk communication, researchers have identified the need for those either listening to or directly involved in risk management dialogues in a range of settings to appreciate the differences in how sections of society will perceive risk in general (Covello et al. 1984; Merkhofer 1987; Slovic 1999). Where these differences have not been sufficiently recognised and/or appropriately responded to in public health or environmental contexts, public mistrust has increased (Slovic 1999; Trettin and Musham 2000; POT 2001). Some of the social research on aquaculture in Europe, Canada and Australia suggests that insufficient attention has being paid to risk perceptions and communication, which is likely to have negative short- and long-term consequences for the industry (Kaiser and Stead 2002; Fraser and Beeson 2003; Mazur et al. 2004a, b; Mazur et al. 2005).

\section{Methods}

This article draws upon data collected during a 3-year program of research undertaken in partnership with the Australian government Department of Agriculture, Fisheries and Forestry (DAFF), the Victorian and South Australian state governments and key sectors of the Australian aquaculture industry. A series of reports has been published under the broad title of the Community Perceptions of Aquaculture Project (CPAP) (Mazur 2004; Mazur et al. 2004a, b; Mazur et al. 2005). The broad objectives of CPAP were to contribute to the long-term viability of aquaculture by helping government, stakeholders and communities to understand the different perspectives held about aquaculture, and to develop more 
responsive policies and programs and improve communications, consultation and participation processes.

Given the largely regional character of the Australian aquaculture industry, the CPAP used a case study approach that enabled in-depth exploration of community perceptions of the industry. There will be a variety of individuals and groups who have a specific interest in aquaculture (communities of interest), as well as those who are interested in aquaculture because they live in close proximity to aquaculture sites (place-based communities) (Petts and Leach 2000; Aslin and Brown 2002). In order to access the breadth and depth of community views and social contexts, a mix of qualitative and quantitative data collection methods were employed: interviews with key stakeholders, a survey mailed to the public and the analysis of data obtained through recent census collections.

\section{Aquaculture and the case study regions}

Australian aquaculture is a diverse industry (Fig. 1). Five sectors contribute to the bulk $(91 \%)$ of the industry's gross value of production (GVP): southern blue-fin tuna (Australian \$261 million), pearls (Australian \$175 million), Atlantic salmon (Australian \$112 million), edible oysters (Australian \$57 million) and prawns (Australian \$65 million) (Love and Langenkamp 2003). The remaining 9\% of the industry's GVP is comprised mainly of other finfish (trout, barramundi and inland freshwater fish), freshwater crayfish and mussels (Love and Langenkamp 2003).

The Eyre Peninsula, South Australia (SA) was selected as one of the CPAP case study regions (Fig. 1). In South Australia, the aquaculture industry is worth approximately Australian \$325 million (PIRSA 2004). The industry has developed rapidly and includes nine species of fish and molluscs. Those farmed on the Eyre Peninsula's coastal regions include Pacific oysters, abalone, southern blue-fin tuna, kingfish, blue mussels and snapper.

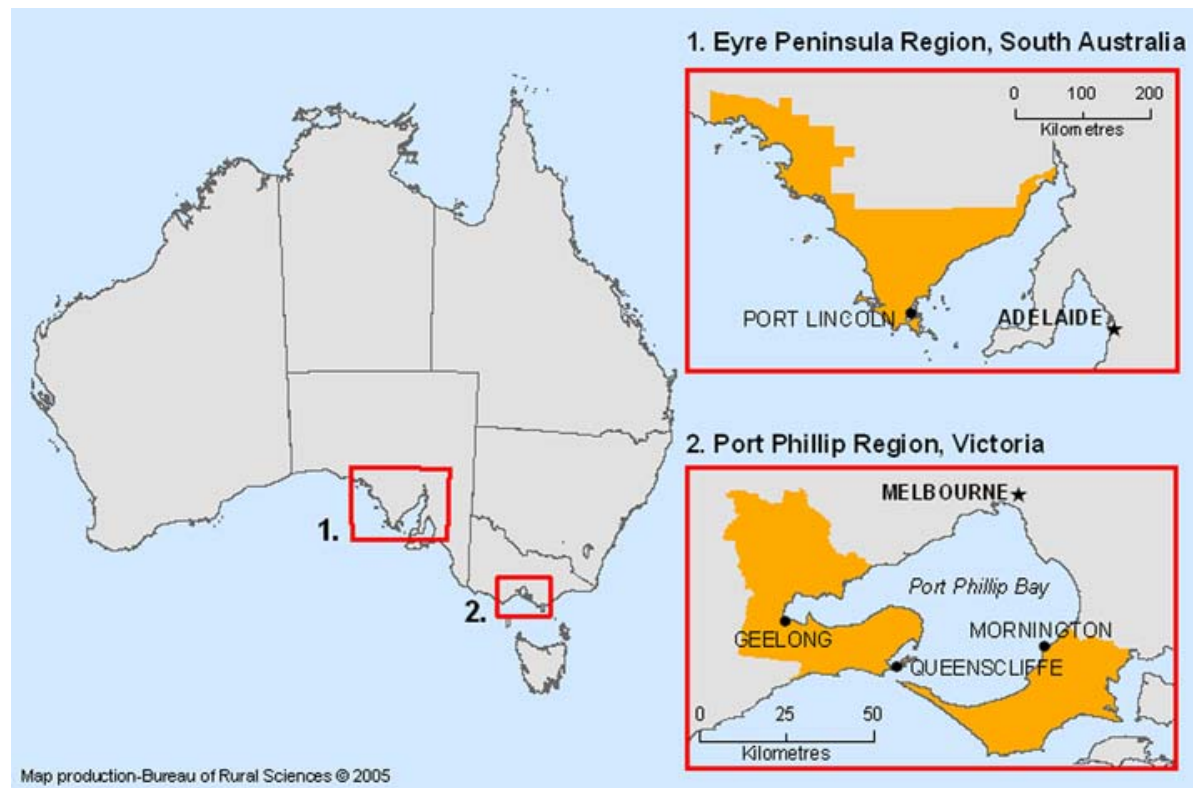

Fig. 1 Australian aquaculture and the CPAP case study locations 
The Eyre Peninsula is a large, remote region situated in western SA with a population of approximately 30,000. The top industries by employment in the region include agriculture (wheat, barley, wool, livestock), tourism and retail, and service sectors. The region's natural features, particularly its remoteness and marine and coastal environments, figure prominently in its tourism industry. The aquaculture industry is of particular interest to Eyre Peninsula residents, as well as those living in other parts of South Australia, in part because it includes several of Australia's highest value sectors. While the fishing sector represents less than $10 \%$ of employment for coastal town residents, well over half of that employment is in aquaculture (ABS 2001). In 2002, there were approximately 1,200 people directly employed by the industry (EconSearch 2003).

The Port Phillip Bay region in Victoria was selected for the second CPAP case study (Fig. 1). The Victorian aquaculture industry was valued at approximately Australian \$21 million in 2002/2003, and has evolved into three main sectors, including inland (salmonids, eels, warm-water native fish and yabbies), marine (mussels and abalone) and ornamental fish (goldfish, tropical fish) (DNRE 2003). Victoria remains the main mussel-producing state in Australia, with production focussed in Port Phillip and Western Port Bays. In contrast to the Eyre Peninsula, the Port Phillip Bay region features both highly urbanised and semirural towns on the outskirts of greater Melbourne, providing a combination of seaside village and city lifestyles. The combined population for the three towns included in the study was 311,496, and the greater metropolitan area of Melbourne has a population of approximately 2.5 million people (ABS 2001). The retail and associated sectors (accommodation, restaurants) were the top employing industries in these towns, and manufacturing and health services also figure highly in their economies. Employment in the fishing industry represented a negligible percentage of total industry employment, whereas for one of the towns (Geelong), $73.8 \%$ (45) of the people employed in the fishing sector were aquaculture employees (ABS 2001). While the region's (and the state's) aquaculture industry is smaller in production and dollar value terms than on the Eyre Peninsula, it provides an important example of resource access issues: Victoria has the highest population-tocoastline ratio of all the Australian states and territories, and coastal environmental and economic resources are highly valued.

\section{Interview process}

The target population for the interview sample needed to reflect the diverse interests in aquaculture: coastal management, industry development, commercial and recreational fishing, fish processors, tourism, recreational groups, conservation groups, and other community groups. Specific groups and individuals from the interest areas were identified through a modified version of snowball or chain sampling (Patton 1990).

Sixty-six interviews were conducted using a modified standardised open-ended interview approach (Patton 1990). The purpose of the interviews was to identify issues of interest to people living near aquaculture and/or had particular interest/involvement in the two regions. The interview schedule was designed to elicit information about:

- aquaculture values

- perceived challenges associated with the industry

- levels of trust in government and the industry

- ways to improve government, industry and community dialogues 


\section{Mail survey}

The population from which the survey sample was selected was adults living in coastal areas along the Eyre Peninsula and Port Phillip Bay regions. Names were randomly selected from the White Pages telephone directory 2003 on CD-ROM. In South Australia (SA), 500 residents in five towns were targeted. A total of 273 residents returned completed surveys, making a response rate of $68 \%$. Three hundred and fifty residents from the City of Greater Geelong (including the Borough of Queenscliffe) and 350 residents from the Mornington Peninsula Shire were targeted. A response rate of 59\% (327) was achieved. Comparisons with Australian Bureau of Statistics data for the case study areas on age, sex and education revealed few differences between the survey sample and the wider population, with the following exceptions:

- more males in the Eyre Peninsula sample

- more 40-59-year olds in Eyre and Port Phillip samples, and fewer 20-39-year olds in Eyre

- more people in the Eyre Peninsula sample with trade and university qualifications and more people in Port Phillip with university qualifications

The mail survey included questions to explore:

- respondents' knowledge about, interest in and levels of contact with the aquaculture industry

- opinions about aquaculture's social and environmental benefits and impacts

- level of trust in government and industry

- risk perceptions

The survey design and mail out procedures were those used by Curtis et al. (2005) who applied and refined Dillman's (1978) total design method.

\section{Results}

Awareness and knowledge

Adults living close to aquaculture activities were targeted for the mail survey in order to test their awareness and knowledge of aquaculture matters. In most cases, the majority of mail survey respondents rated their knowledge as 'low', and they felt they knew least about the roles of the state and local government and the indigenous communities' interest/ involvement in the industry. Claims of knowledge were highest in relation to aquaculture impacts on coastal recreation, storm-water impacts on aquaculture, and marine ecology. Levels of awareness differed between the regions, for example:

- four times as many Eyre Peninsula respondents $(63 \%, n=263)$ as Port Phillip Bay respondents $(17 \%, n=326)$ said they had thought about aquaculture issues prior to the survey

- far more Port Phillip Bay respondents (89-95\%, $n=306-309)$ than Eyre Peninsula respondents $(53-77 \%, n=262-263)$ gave themselves low knowledge ratings in relation to governments' role in aquaculture

- similarly, many more Port Phillip Bay respondents $(71-82 \%, n=308-310)$ than Eyre Peninsula respondents $(30-56 \%, n=262-264)$ felt they knew 'little or nothing' about aquaculture industry sectors or practices 
Mail survey respondents used varied sources to obtain information about aquaculture. Other research (Aslin and Byron 2003) and the Port Phillip Bay case study (see Mazur et al. 2004b) show that sources of information on the fishing industry rated most important often receive lower credibility ratings (e.g. media, governments), while sources used less frequently receive higher credibility ratings (e.g. universities/research centres, the fishing industry, libraries, the Internet, personal experience).

\section{Socioeconomic benefits}

Most interviewees recognised aquaculture's socioeconomic benefits, such as its contribution to local economies in rural and remote regions. Eyre Peninsula interviewees recognised these benefits slightly more strongly than most Victorian interviewees, who focused mainly on the industry's environmental sustainability:

"Aquaculture is the jewel in the crown of the Eyre Peninsula ... it is a huge employer [that] generates wealth, especially in small towns, quickly." (Eyre Peninsula industry interviewee)

"Well, the good stuff is about sustainability ... it's about things like nutrient reduction programs. I feel there's enormous potential for that ... it's the particular strength of shellfish aquaculture. Other forms of aquaculture ... it does provide some opportunities for improved productivity and potentially some benefits [for] ecosystems." (Port Phillip community interviewee)

Many mail survey respondents rated aquaculture's benefits more highly than its disadvantages and agreed that the industry had flow-on benefits for the region (other industries, employment) (Table 1). The Port Phillip respondents were less certain about these advantages than their Eyre Peninsula counterparts. Eyre Peninsula respondents linked socially to the aquaculture industry were more likely to agree that the industry's benefits outweighed any disadvantages [63\% with links agreed, 49\% without links agreed $\left(\chi^{2}=17.590\right.$, df $\left.\left.=6, P=0.007\right)\right]$, and a similar result was found for Geelong respondents $\left[45 \%\right.$ Geelong respondents agreed, $37 \%$ Mornington agreed $\left(\chi^{2}=12.772\right.$, df $=6$, $P=0.047)]$.

\section{Environmental sustainability}

Many interviewees placed high value on the environment, particularly coastal and marine settings in their respective regions:

"I value the serenity and peacefulness of the place, its clean waters, non-commercial areas free from pollution and traffic .. the biodiversity, the marine and bird life." (Eyre Peninsula community interviewee)

"The natural diversity of this area ... I think is quite important. We have rough cliff areas through to flat sandy beaches, through to mangroves ... we've got surf beaches, national parks ... and a community very aware of environmental issues." (Port Phillip local government interviewee)

Mail survey respondents also showed strong environmental interests. A majority rated environmental impacts as the most important aquaculture issue, followed by the industry's economic contribution and its impacts on other users of coastal and marine resources. 
Table 1 Mail survey respondents' views on aquaculture's environmental sustainability—2003

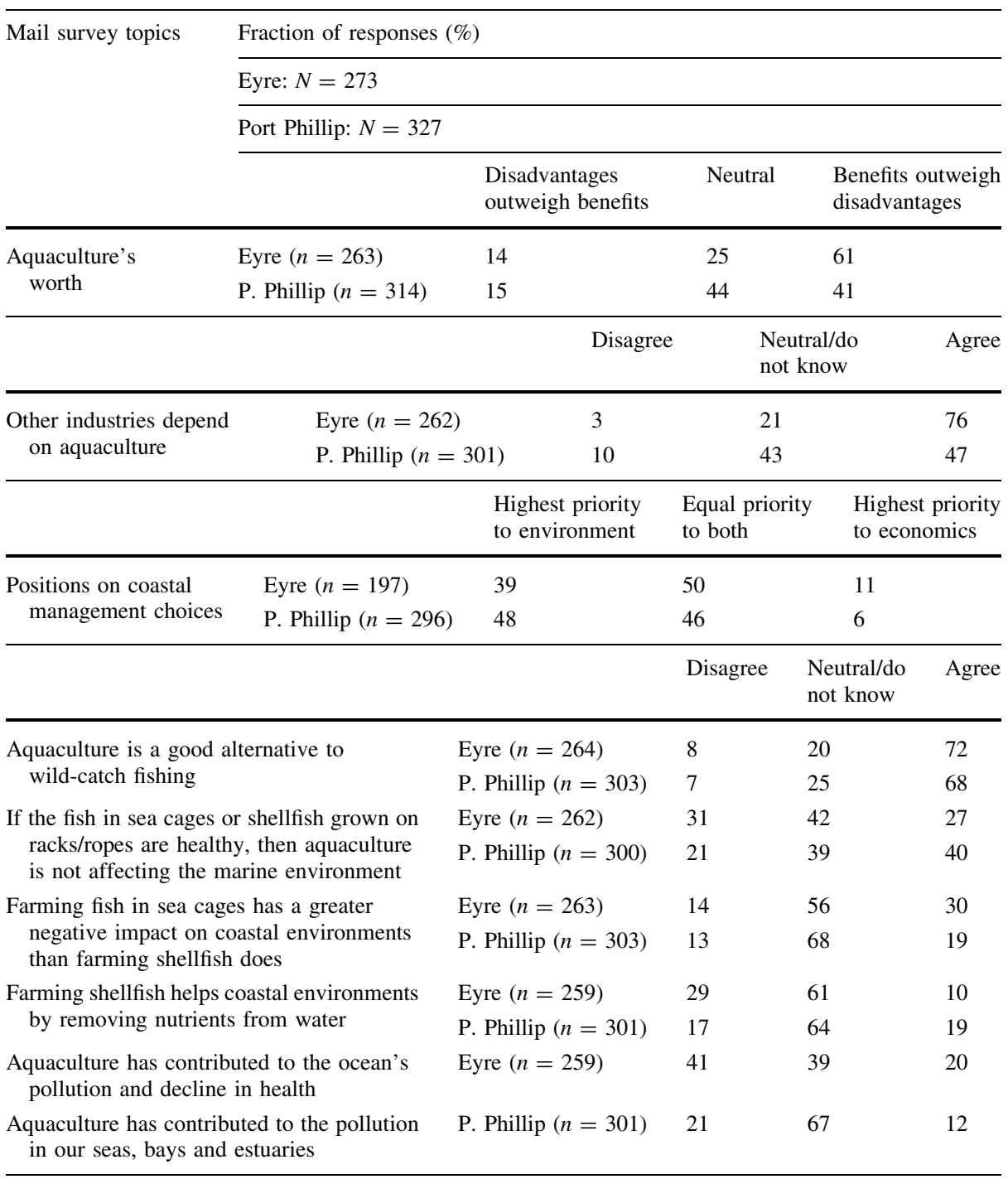

A majority agreed that aquaculture generally provides a good or at least equally acceptable alternative to wild-caught seafood. There was also some uncertainty about aquaculture's environmental strengths, which rose considerably when respondents were asked more detailed questions (Table 1).

More Port Phillip Bay respondents were unclear about these matters than were Eyre Peninsula respondents (Table 1). Compared to their Eyre Peninsula counterparts, the Port Phillip Bay mail survey respondents generally had stronger environmental values: more endorsed increasing marine protected areas in their region (54\% of Port Phillip respondents, $34 \%$ of Eyre Peninsula respondents) and a higher proportion prioritised the environment over the economy in coastal management choices (see Table 1). We found that respondents 
who were more concerned about aquaculture's environmental impacts were more likely to be female, have higher levels of education, be members of coastal management/ conservation groups and to have visited Victorian aquaculture sites (see Table 2).

\section{Trust and environmental performance}

Interviewees in both regions had mixed levels of trust in the aquaculture industry, but used similar criteria when making their judgements: the motivations and performance of different industry sectors; the adequacy of environmental regulations and their enforcement; and the presence and intensity of environmental problems/issues:

\footnotetext{
"Some [sectors] are doing very well ... the Abalone sector is in its early stages and has substantive input from science and good financial backing ... smaller scale players in any sector will be more squeezed for money, knowledge, skills and infrastructure." (Port Phillip government interviewee)

"Many individual operators try to do the right thing. But my personal dealings with [the aquaculture industry] suggests financial imperatives take precedence over environmental imperatives. I have seen the industry misrepresent community views." (Eyre Peninsula community interviewee)
}

Mail survey respondents also rated their trust in the industry and its environmental performance. There were varying levels of trust in different industry sectors (Table 3). Many respondents (one quarter to half) were uncertain about trusting the industry. More respondents trusted the South Australian shellfish and tuna sectors than trusted the South Australian kingfish and Victorian sectors. There was more uncertainty among the Port Phillip respondents than the Eyre Peninsula respondents. Nearly half the Port Phillip Bay respondents felt the aquaculture industry could do more for the environment, while a similar percentage of Eyre Peninsula respondents supported the industry's environmental responsibility and response to controversy (Table 3 ).

Mail survey respondents more likely to trust the aquaculture industry included those who had visited aquaculture farms or knew someone in the industry, and/or were longstanding residents of the Eyre Peninsula (Table 4). However, Eyre Peninsula respondents with social links to the industry were less likely to trust the sea-cage sector of the industry (Table 4). Other respondents less likely to trust the industry included women and those with higher levels of education (Table 4).

Mail survey respondents rated the risk that different aquaculture sectors would have some kind of negative environmental impact in the next 5-10 years (Table 3). Generally, more respondents were concerned about environmental risks from sea-cage sectors (e.g. kingfish, tuna) than from the shellfish sectors (e.g. mussels, abalone, oysters) (Table 3). Overall, there were high levels of uncertainty about aquaculture's future impacts. More Port Phillip respondents were unsure about aquaculture's environmental risks than were the Eyre Peninsula respondents, although respondents from the two regions were equally unsure about the mussel sector (Table 3).

\section{Trust in government}

When rating their trust in governments' aquaculture-related decisions, interviewees from both regions made judgments on the perceived impartiality of decision makers, their 

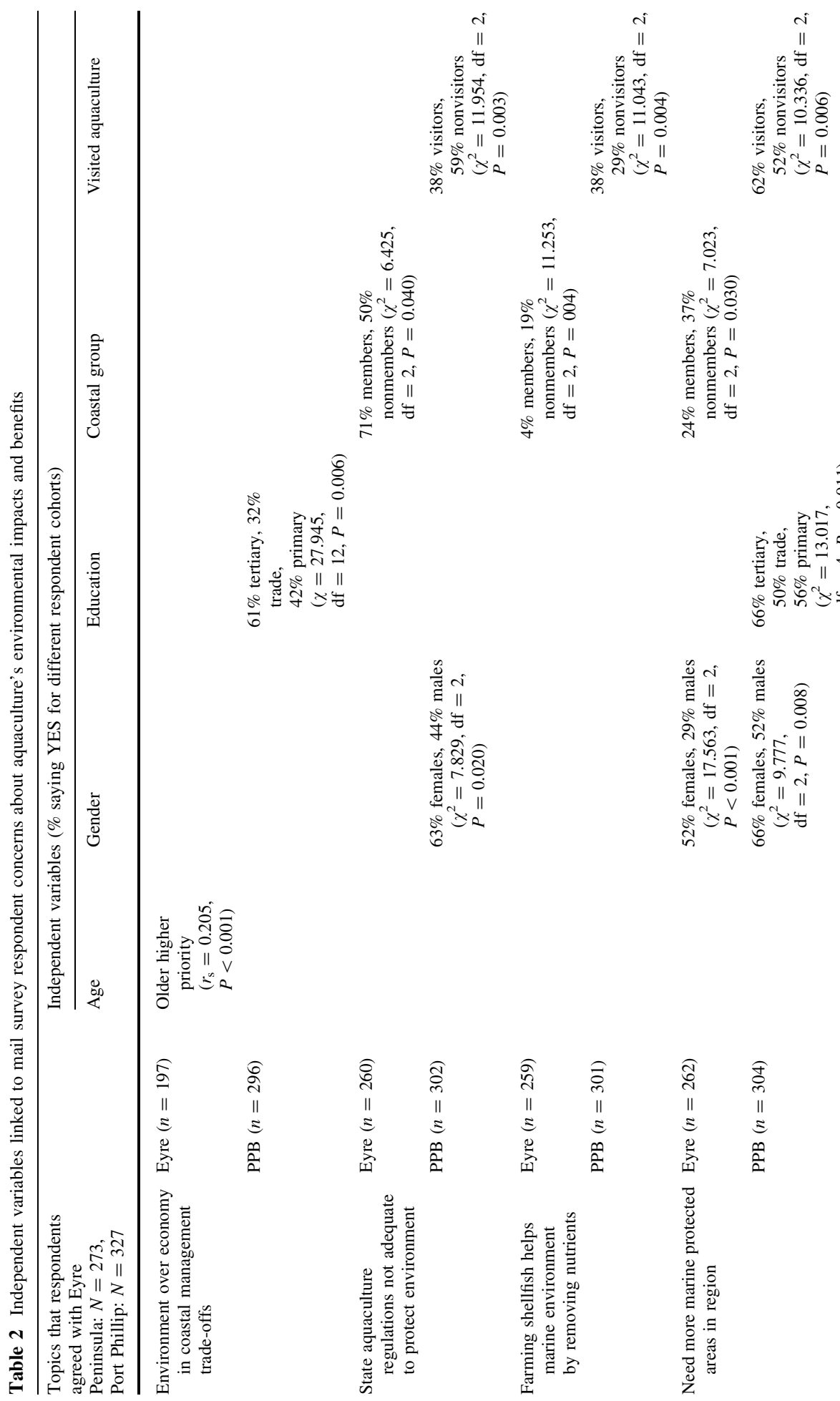

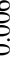$$
\text { (1) }
$$ 


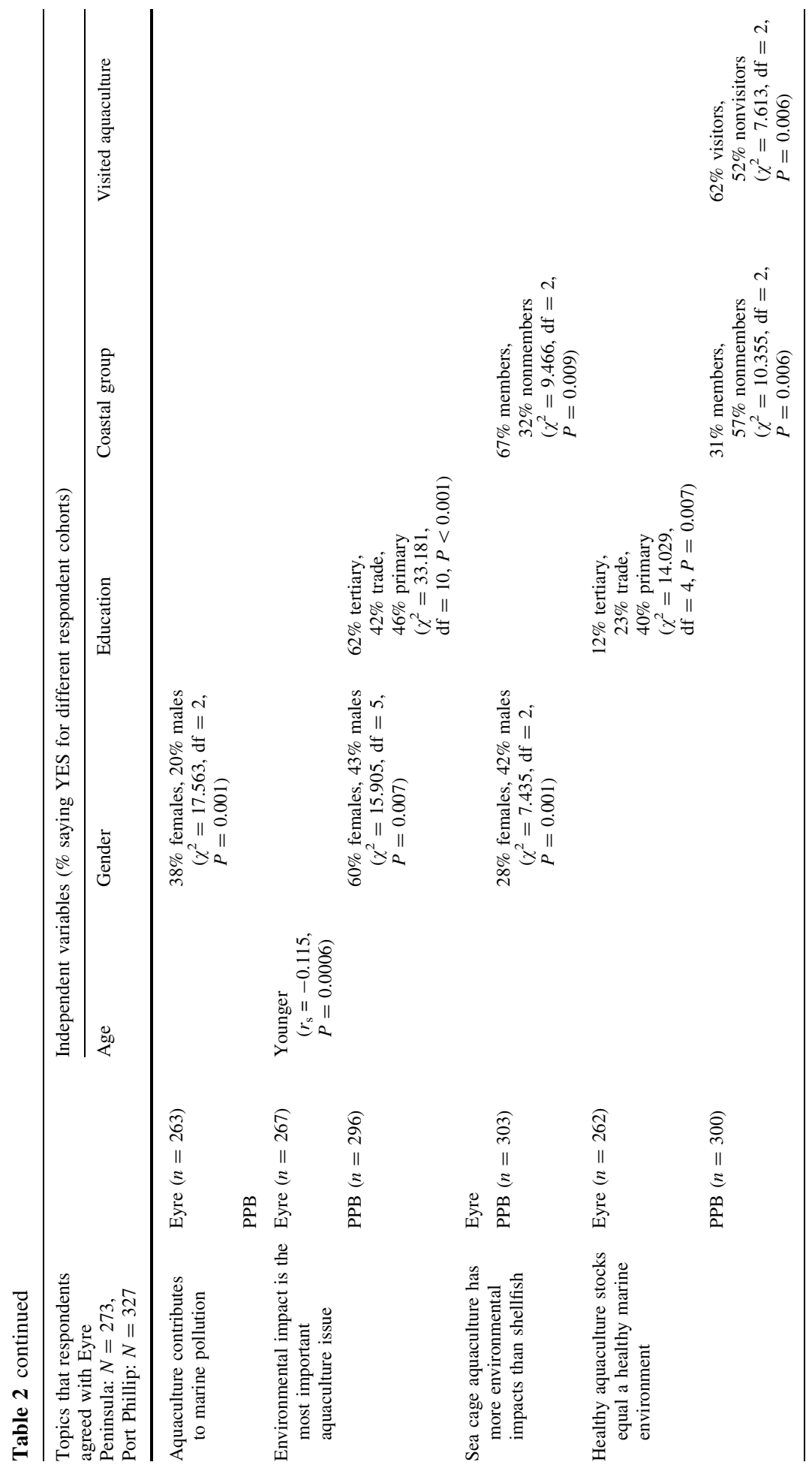


Table 3 Mail survey respondents' risk perceptions and levels of trust-2003

\begin{tabular}{|c|c|c|c|c|c|c|c|}
\hline \multirow{2}{*}{$\begin{array}{l}\% \text { of mail survey respondents } \\
\text { Port Phillip: } N=327 \\
\text { Eyre Peninsula: } N=273\end{array}$} & \multicolumn{7}{|c|}{ Level of trust in the quality of industry decisions } \\
\hline & \multicolumn{2}{|c|}{ Lower trust } & \multicolumn{2}{|c|}{ Unsure } & \multicolumn{3}{|c|}{ Higher trust } \\
\hline Aquaculture industry-Port Phillip $(n=302)$ & \multicolumn{2}{|l|}{26} & \multicolumn{2}{|l|}{50} & \multicolumn{3}{|l|}{24} \\
\hline Aquaculture industry-Eyre Peninsula $(n=259)$ & \multicolumn{2}{|l|}{20} & \multicolumn{2}{|l|}{25} & \multicolumn{3}{|l|}{55} \\
\hline Abalone_-Port Phillip $(n=302)$ & \multicolumn{2}{|l|}{33} & \multicolumn{2}{|l|}{48} & \multicolumn{3}{|l|}{19} \\
\hline Abalone-Eyre Peninsula $(n=261)$ & \multicolumn{2}{|l|}{13} & \multicolumn{2}{|l|}{35} & \multicolumn{3}{|l|}{52} \\
\hline Mussels_-Port Phillip $(n=302)$ & \multicolumn{2}{|l|}{29} & \multicolumn{2}{|l|}{49} & \multicolumn{3}{|l|}{22} \\
\hline Mussels_-Eyre Peninsula $(n=258)$ & \multicolumn{2}{|l|}{10} & \multicolumn{2}{|l|}{50} & \multicolumn{3}{|l|}{40} \\
\hline Kingfish-Eyre Peninsula $(n=260)$ & \multicolumn{2}{|l|}{45} & \multicolumn{2}{|l|}{31} & \multicolumn{3}{|l|}{24} \\
\hline Tuna-Eyre Peninsula $(n=259)$ & \multicolumn{2}{|l|}{28} & \multicolumn{2}{|l|}{29} & \multicolumn{3}{|l|}{43} \\
\hline Oysters-Eyre Peninsula $(n=260)$ & 9 & & 19 & & 72 & & \\
\hline Perceived risk of future negative environmental im & pacts & Lower $\mathrm{r}$ & & Unsur & & Hig & her risk \\
\hline Mussels_-Port Phillip $(n=299)$ & & 34 & & 44 & & 22 & \\
\hline Mussels_-Eyre Peninsula $(n=260)$ & & 46 & & 40 & & 14 & \\
\hline Abalone-Port Phillip $(n=298)$ & & 28 & & 46 & & 26 & \\
\hline Abalone-Eyre Peninsula $(n=261)$ & & 58 & & 25 & & 17 & \\
\hline Oysters-Eyre Peninsula $(n=259)$ & & 61 & & 19 & & 20 & \\
\hline Tuna-Eyre Peninsula $(n=261)$ & & 36 & & 23 & & 41 & \\
\hline Kingfish-Eyre Peninsula $(n=261)$ & & 16 & & 23 & & 61 & \\
\hline Trust in governments' aquaculture-related decisions & & Lower trust & & Unsure & & Hig & er trust \\
\hline Australian government—Port Phillip $(n=302)$ & & 50 & & 23 & & 27 & \\
\hline Australian government-Eyre Peninsula $(n=262)$ & & 33 & & 36 & & 31 & \\
\hline State government-Port Phillip $(n=300)$ & & 43 & & 23 & & 34 & \\
\hline State government-Eyre Peninsula $(n=262)$ & & 36 & & 23 & & 41 & \\
\hline Local government-Port Phillip $(n=302)$ & & 43 & & 29 & & 28 & \\
\hline Local government-Eyre Peninsula $(n=258)$ & & 26 & & 20 & & 54 & \\
\hline & & & & agree & Unsur & & Agree \\
\hline $\begin{array}{l}\text { SA's environmental protection laws not adequate } \\
\text { when it comes to aquaculture }(n=260)\end{array}$ & & & 15 & & 43 & & 42 \\
\hline $\begin{array}{l}\text { Victoria's aquaculture controls not strong enough t } \\
\text { the environment }(n=302)\end{array}$ & prot & & 8 & & 59 & & 33 \\
\hline Aquaculture companies could do more for the envi & ronme & $\mathrm{t}(n=300)$ & 3 & & 53 & & 44 \\
\hline $\begin{array}{l}\text { Environmental controversies treated responsibly by } \\
\quad \text { industry }(n=263)\end{array}$ & aquac & llture & 12 & & 42 & & 46 \\
\hline $\begin{array}{l}\text { Aquaculture companies do not care about environm } \\
\text { management }(n=261)\end{array}$ & ental & & 48 & & 32 & & 20 \\
\hline
\end{tabular}

accessibility, and how responsive they were to different interests and environmental problems related to aquaculture.

"I have low trust. Governments are scared not to promote industry, which is why we can get development in inappropriate places. Their consultation report didn't 


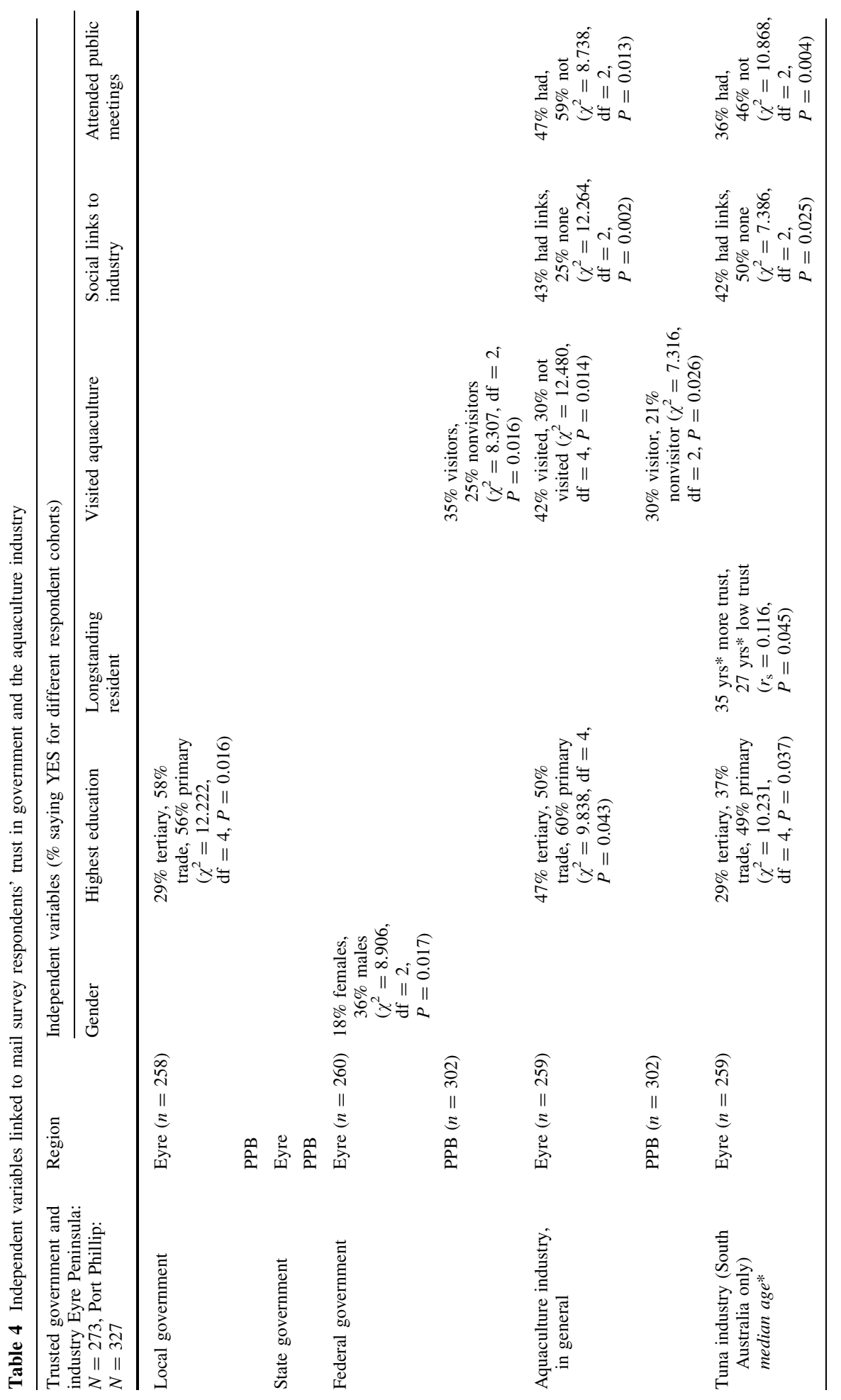




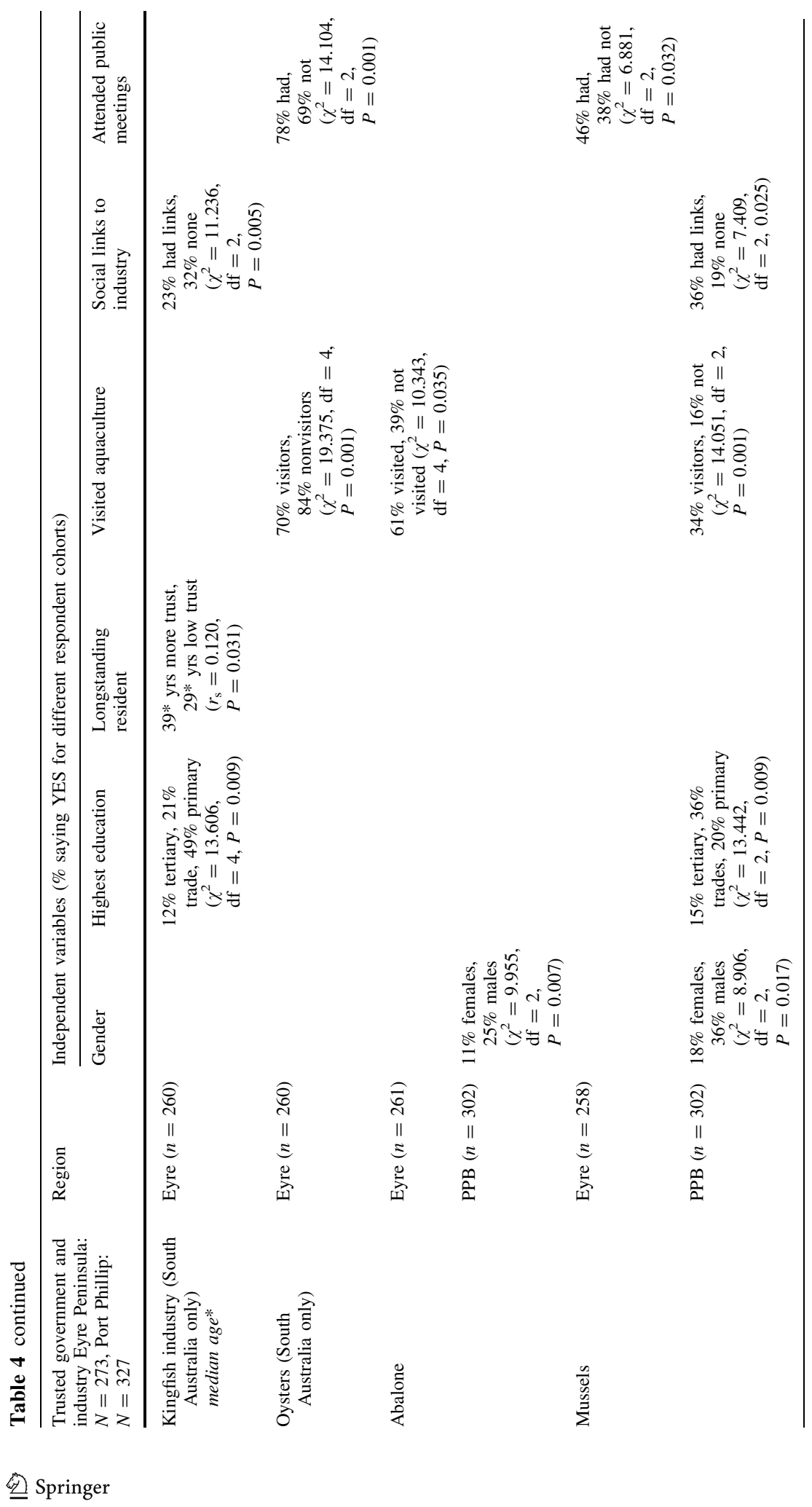


reflect our concerns about some aquaculture sites." (Port Phillip community interviewee)

Mail survey respondents also had varied levels of trust in the national, state and local government aquaculture-related decisions and procedures (Table 3). A quarter to one half of all respondents had low levels of trust. A significant minority were unsure how much they trusted governments and more were unsure about the adequacy of aquaculture's environmental regulations (Table 3).

More Eyre Peninsula respondents than Port Phillip Bay respondents had high levels of trust in government, particularly in local and state governments, and were satisfied with aquaculture's environmental regulations (Table 3). Mail survey respondents less likely to trust government aquaculture decisions were female (see Tables 2 and 4), those involved with South Australian coastal groups (Table 2) and people who attended public meetings about aquaculture on the Eyre Peninsula (62\% attendees, $42 \%$ nonattendees, $\chi^{2}=7.357$, $\mathrm{df}=2, P=0.025)$.

\section{Building trust/reconciling differences}

Interviewees in both case studies had the opportunity to discuss ways to improve trust among governments, the aquaculture industry and communities. While views within regions varied to some degree, there was a strong focus in both case studies on the following themes:

- greater transparency of (state, and to a lesser degree local) government decisions relating to aquaculture

- improved communication and coordination between state and local governments for aquaculture development, planning and management

- firm government regulations and incentives to reassure (place- and interest-based) communities that the aquaculture industry's environmental impacts will be prevented and/or minimised

- clear, accessible and regular information about those requirements

- improved consultation with and engagement of (place- and interest-based) communities that seek to build trust, are continuous, interactive, more timely (take place as early as possible in decision making) and include a more diverse range of interests

- building the aquaculture industry's capacity for environmental management and community consultation/engagement

Mail survey respondents in both regions also highly valued the principle of the public 'having a say' in aquaculture planning. Seventy-one percent $(n=273)$ of Eyre Peninsula respondents and $62 \%(n=327)$ of Port Phillip respondents believed that the benefits of community participation outweighed any costs incurred by governments or industry in facilitating that input. Approximately a third of mail survey respondents expressed interest in being involved in aquaculture planning. There was stronger support for interactive forms of participation than for the passive, more traditional forms (e.g. making written submissions, public meetings). Respondents who knew someone in the Victorian aquaculture industry were less likely to support public participation (8\% with links, $15 \%$ without links, $\chi^{2}=13.315$, df $=6, P=0.038$ ), while those with social links to the SA industry $\left(73 \%\right.$ with links, $56 \%$ without links, $\left.\chi^{2}=18.498, \mathrm{df}=6, P=0.005\right)$ and those who had attended aquaculture public meetings in Victoria (30\% attendees, $11 \%$ nonattendees, $\chi^{2}=14.292$, $\mathrm{df}=6, P=0.027$ ) were more likely to be supportive. 


\section{Discussion}

Natural resource management in Western societies is characterised by diverse and often conflicting expectations about how to allocate and manage resources and achieve efficient and equitable social, economic and environmental outcomes. Identifying the range of values and beliefs about the sustainability of natural resource use is a vital ingredient in successful management of resource allocation issues. It is also essential that the diversity of perspectives is represented and informs decision making, including discussions about trade-offs (social, economic, environmental).

Most interviewees and mail survey respondents in our research were able to identify the socioeconomic benefits of the aquaculture industry, but there were mixed opinions about the industry's environmental sustainability. Eyre Peninsula mail survey respondents were more aware and supportive of the industry's socioeconomic contributions. Interview and mail survey respondents placed a high value on the marine and coastal settings in their regions, and Port Phillip mail survey respondents had even stronger values for the environmental values of these settings. Indeed, half of the Port Phillip mail survey respondents and a third of Eyre Peninsula mail survey respondents gave a higher priority to the environment over the economy in broader coastal management. Interview and mail survey respondents expressed strong concerns about aquaculture's environmental impacts. These concerns were stronger amongst mail survey respondents with higher education levels, those belonging to coastal groups or those who were female. Generally, there were high levels of uncertainty among mail survey respondents about the industry's environmental benefits.

Other studies of how the public values the natural environment suggest that the broader public favours the environment over economic values when asked to make decisions involving trade offs between economic and environmental values (Connelly and Knuth 2002; Nancarrow and Syme 2001; Tarrant et al. 2003). Research in Mexico and Greece established that the aquaculture industry's social acceptability was improved where local concerns about environmental damage from aquaculture were low, perceived socioeconomic benefits were high and location and management regimes were considered suited to the region (Hugues-Dit-Ciles 2000; Katranidis 2003).

Similar to Shindler et al. (2002b), we believe that the greater the perceived risk (or the uncertainty about risk potential) the less acceptable both the aquaculture industry's and governments' planning and management activities will be. The CPAP results showed that levels of trust in governments and the aquaculture industry varied across the interview and mail survey respondents. Their judgments were informed by their perceptions and experiences of governments' accessibility and impartiality and the industry's motivations and environmental performance. In addition, some aquaculture industry sectors (shellfish versus sea cages) had higher levels of trust and were perceived to represent lower levels of risk to the environment. The characteristics of risks and the sociopolitical context of decision making influence how people respond to risk issues (Beckwith et al. 1999; Slovic 1999).

An additional consideration is that sociodemographic characteristics (race, religion), gender, behaviour patterns and experiences inform people's perceptions of environmental risk and what constitutes effective governance (Slovic 1999; Palmer 2003; Anthony et al. 2004). In our case studies, women, community groups (particularly those with conservation interests), ecotourism industries, some researchers, local governments, some state agency staff and informed members of the general public were more likely to focus on aquaculture's negative (environmental, economic and social) risks and seek 
improvements in aquaculture planning and management to substantially reduce those risks.

Regional settings and conditions can also affect perceptions of aquaculture, including the size and structure of the aquaculture industry, the extent of regional economic diversity, population densities and the resulting pressures on coastal and marine environments and previous history of aquaculture-related conflicts. For example, compared with Victoria, the South Australian aquaculture industry has a much larger economic impact in a region with a much narrower economic base. In turn, the higher public visibility and economic impact of the industry in the Eyre Peninsula may be part of the reason why survey respondents in that region had higher levels of awareness and knowledge of aquaculture, higher levels of support and trust in the industry and higher levels of trust in government processes than did respondents in the Port Phillip region.

On the other hand, the Port Phillip region is adjacent to the large city of Melbourne and has much higher population densities than in the Eyre Peninsula. As might be expected, aquaculture faces much stronger competition for access to highly valued marine and coastal environments in the Port Phillip region. There have also been local conflicts in the Port Phillip area over aquaculture developments, as well as highly publicised controversies over proposed developments in the region's national park.

\section{Conclusions}

The CPAP findings suggest that there is potential to improve the social acceptability of the aquaculture industry and governments' aquaculture policies and programs. Improving public awareness and support for aquaculture should include attention to communications programs, information provision and public participation, which are discussed further below.

The CPAP results suggest that large parts of the general public may be relatively uninformed about a range of aquaculture-related topics. However, awareness and knowledge levels will probably vary between regions, in relation to industry sectors and practices and according to communities' sociodemographic characteristics, behaviours, experiences and interests. Not all members of the public will be interested in aquaculture, but there is considerable opportunity to increase public awareness and understanding of the industry. Information programs could target topics that people are least likely to know about and be tailored to different aquaculture regions and industry sectors. The information needs and interests of more informed audiences will differ.

It will be increasingly important to understand and value the different ways societal groups perceive risk, particularly the risk that aquaculture might have negative social and environmental impacts. In other natural resource and public health contexts, differences between expert and lay public perceptions of risk have been neglected when authorities rely on older communication models (Slovic 1999; POT 2001). In these situations, experts may use increasing amounts of technical information to convince the public that the risk is negligible and/or under control and rely on one-way information delivery, which is known to exacerbate public concerns rather than build trust (Slovic 1999; Petts and Leach 2000).

Improving public trust also requires that key communications messages and activities are designed to disprove some of the more commonly held negative stereotypes of governments and industries (Peters et al. 1997). The aquaculture industry will need to demonstrate its transparency and accountability, and its concern for the public interest and environmental protection. Similarly, governments need to demonstrate their commitment 
and ability to prevent or lessen negative environmental (and social) impacts and to be responsive to a wide range of interests.

Easy access to credible information is another key component to building public trust in aquaculture. It will be valuable for governments and the aquaculture industry to investigate further ways to increase the use of information sources seen as more credible (e.g. public radio, direct contact with the aquaculture industry, universities/research centres). Selective use of the important but less credible sources, such as the mass media, is warranted. In addition, governments may wish to explore improving the use and credibility of their public information on aquaculture.

More innovative participatory strategies and fora could complement existing community consultation activities, thereby increasing the effectiveness of decision making and building public trust (Kaiser and Stead 2002; Mazur et al. 2005). These initiatives should ideally be more inclusive, occur earlier in decision making, match methods to clearly stated objectives, be delivered at regional/local scales by people with credibility and community engagement expertise and offer genuine opportunities to influence decisions (Shindler et al. 2002b).

Some parts of the public are more likely to support or oppose aquaculture, depending on sociodemographic features of communities, people's experiences, aquaculture industry sectors and practices and other factors (Mazur et al. 2004a, b; Mazur et al. 2005). In addition, interest-based communities, such as the ones identified in this project, are likely to be more informed and interested in being involved in decision making (Brown et al. 2001; Aslin and Brown 2002). Communicating about aquaculture-whether simply providing information or by involving the public in decision making-will be more effective when it is tailored to those differences.

Governments and the aquaculture industry should continue to share responsibility for increasing the use of more comprehensive assessment of community perceptions of aquaculture and its impacts. The following areas of social research can generate knowledge needed to underpin a sustainable industry that has the widest possible social and economic benefits and imposes negligible environmental damage:

- building governmental and industry capacity to undertake regular and comprehensive social research, social impact assessment, and community consultation

- developing consistent and extensive social criteria to complement biophysical criteria used in resource assessments, project feasibility studies and development approvals

- developing conflict prevention and management models to suit aquaculture situations

- identifying how negative public perceptions of aquaculture are formed

- further exploration of how the public perceives aquaculture's risks to the environment and human health and how those perceptions vary across societal groups

- undertaking education and training inventories to identify the necessary knowledge and skills for understanding aquaculture's social dimensions, which could then be incorporated into curricula, competency standards and accreditation schemes for employees, consultants and trainers in the aquaculture industry

The CPAP has demonstrated the potential benefits of social research informing decisions about aquaculture planning and management. Understanding community views, particularly how the risks associated with aquaculture are perceived, and engaging communities in meaningful and interactive dialogues, is an essential part of preventing conflicts and building a more socially acceptable aquaculture industry. In turn, the CPAP research has added to the limited body of international literature on this topic, providing insights about how aquaculture is perceived by the public and demonstrating the utility of case study research for examining aquaculture's social dimensions and impacts. 
Acknowledgements This research was funded by the Australian Government's Department of Agriculture, Fisheries and Forestry and the Victorian Department of Primary Industries and took place while Nicole Mazur was employed by the Bureau of Rural Sciences (BRS) in 2003-2005. The authors would like to thank Heather Aslin and Ian Byron of the Bureau of Rural Sciences who were CPAP team members, as well as Glenn Hurry, John Talbot and Andrew Buckley of the Department of Agriculture, Fisheries and Forestry; Anthony Forster, Peter Appleford, Gaynor Jones, Peter Lawson, John Mercer and Luke Cromie of Fisheries Victoria; Ian Nightingale and Emily Stutterd of PIRSA Aquaculture; and Aquaculture Committee members of the Australian Fisheries Managers' Forum.

\section{References}

Anthony ML (2004) Gender and citizen participation in wildlife management decisions. Soc Nat Resour 17(5):395-411

Aslin HJ, Brown VA (2002) Research report for good practice community engagement for the MurrayDarling Basin. Bureau of Rural Sciences, Canberra

Aslin HJ, Byron IG (2003) Community perceptions of fishing: implications for industry image, marketing and sustainability. Fisheries Research and Development Corporation and the Bureau of Rural Sciences, Canberra

Australian Bureau of Statistics (2001) Census of population and housing. ABS, Canberra

Bardwell LV (1991) Problem framing: a perspective on environmental problem solving. Environ Manage 15(5):603-612

Beckwith JA, Colgan PA, Syme GJ (1999) Seeing risk through other eyes. In Johnston CD (ed) Contaminated site remediation: challenges posed by urban and industrial contaminants. Proceedings of the 1999 contaminated site remediation conference, Center for Groundwater Studies. CSIRO Land and Water, Wembley, Western Australia, pp 49-56

Black KD (2001) Sustainability of aquaculture. In: Black KD (ed) Environmental impacts of aquaculture. Sheffield Academic Press, Sheffield, UK, pp 199-212

Blackstone L (2001) Environmental consumer research: National Fisheries Institute. Len Blackstone Ad Group

Brown VA, Nicholson R, Stephenson P, Bennett K-J, Smith J (2001) Grass roots and common ground: guidelines for community-based environmental health action. Regional Integrated Monitoring Centre, Sydney

Carvalho P (1998) Results of a South Australian coastal aquaculture survey. Waves and regional ripples (November). Marine and Coastal Community Network, Adelaide, South Australia

Clark TW, Willard AR, Cromley CM (2000) Foundations of natural resources policy and management. Yale University Press, New Haven, CT

Clarke B (1996) Aquaculture management and planning in South Australia: blue farming revolution or goldrush? Masters Thesis, University of Adelaide, South Australia

Connelly NA, Knuth BA (2002) Using the co-orientation model to compare community leaders' and local residents' views about Hudson River ecosystem restoration. Soc Nat Resour 15:933-948

Covello VT, von Winterfeldt D, Slovic P (1984) Communicating scientific information about health and environmental risks: Problems and opportunities from a social and behavioral perspective. In Covello VT, Lave LB, Moghissi A, Uppuluri VRR (eds) Uncertainty in risk assessment, risk management and decision making. Plennum, New York, pp 221-239

Creighton JA, Pinney T, Scott S (1997) Let's get to it: getting beneath difficult environmental resource debates. Harwood Group, Great Plains Partnership \& Minnesota Department of Natural Resources

Curtis A, Shindler B, Wright A (2002) Sustaining local watershed initiatives: lessons from landcare and watershed councils. Journal Am Water Resour Assoc 38(5):1207-1216

Curtis A, Byron I, Mackay J (2005) Integrating socio-economic and biophysical data to underpin collaborative watershed management. J Am Water Resour Assoc 41(3):549-563

Dillman DA (1978) Mail and telephone surveys: the total design method. Wiley Interscience, New York

DNRE (Department of Natural Resources and Environment) (2003) Fisheries Division, NRE Commercial Fish Production Information Bulletin 2003. Marine and Freshwater Resources Institute, Queenscliffe, Victoria, Australia

Donnan DW (2001) Aquaculture in the age of integrated coastal management (ICM). In Black KD (ed) Environmental impacts of aquaculture. Sheffield Academic, Sheffield, UK, pp 183-198

Douglas M (1992) Risk and blame: essays in cultural theory. Routledge, London

Dryzek JS (1997) The politics of the earth. Oxford University Press, Oxford 
EconSearch (2003) The economic impact of aquaculture on the South Australian state and regional economies, 2001/02. EconSearch and Aquaculture Group, Primary Industries and Resources, Adelaide

FAO (2002) State of the world's fisheries and aquaculture 2002. FAO Fisheries Department, Rome. http://www.fao.org/documents/show_cdr.asp?url_file=/docrep/005/y7300e/y7300e00.htm

Fraser JA, Beeson K (2003) The salmon aquaculture forum: discussion paper on practices and findings. Pacific Fisheries Resource Conservation Council, Vancouver

Grimble R, Wellard K (1997) Stakeholder methodologies in natural resource management: a review of principles, contexts, experiences and opportunities. Agric Syst 55(2):171-193

Harding R (1998) Environmental decision-making: the role of scientists, engineers and the public. The Federation Press, Leichhardt, NSW

Hugues-Dit-Ciles EK (2000) Developing a sustainable community-based aquaculture plan for the lagoon of Cuyutlan through a public awareness and involvement process. Coast Manage 28(4):365-383

Kaiser M, Stead SM (2002) Uncertainties and values in European aquaculture: communication, management and policy issues in times of "changing public perceptions". Aquac Int 10:469-490

Katranidis S, Nitsi E, Vakrou A (2003) Social acceptability of aquaculture development in coastal areas: the case of two Greek Islands. Coast Manage 31(1):37-53

Love G, Langenkamp D (2003) Australian aquaculture: industry profiles for related species. ABARE $e$ Report 03.8. Australian Bureau of Agriculture and Resource Economics, Canberra

Mazur N (2004) Community perceptions of aquaculture: related social research. Bureau of Rural Sciences, Canberra

Mazur N, Aslin H, Curtis A, Byron I, Magpantay C (2004a) Community perceptions of aquaculture: report on the Eyre Peninsula. Bureau of Rural Sciences, Canberra

Mazur N, Aslin H, Curtis A, Byron I, Magpantay C (2004b) Community perceptions of aquaculture: report on the Eyre Peninsula. Bureau of Rural Sciences, Canberra

Mazur N, Aslin H, Byron I (2005) Community perceptions of aquaculture: final report. Bureau of Rural Sciences, Canberra

Merkhofer MW (1987) Decision science and social risk management. D. Reidel, Dordecht

MWGA (Ministerial Working Group on Aquaculture) (2003) Strategic framework for Scottish aquaculture. Scottish Executive, Edinburgh

Nancarrow BE, Syme GJ (2001) Stakeholder profiling study: a report to the river Murray environmental flow and water quality objectives project board. CSIRO Land and Water and the Murray Darling Basin Commission, Canberra, Australia

Naylor RL, Goldburg RJ, Primavera JH, Kautsky N, Beveridge MCM, Clay J, Folke C, Lubchenco J, Mooney H, Troell M (2001) Effect of aquaculture on world fish supplies. Nature 405(6790):1017-1024

Patton MQ (1990) Qualitative evaluation and research methods, 2nd edn. Sage, Newbury Park

Palmer CGS (2003) Risk perception: another look at the 'white male' effect. Health, Risk Soc 5(1):71-83

Pauly D, Christensen V, Guenette S, Pitcher TJ, Sumaila UR, Walters CJ, Watson R, Zeller D (2002) Towards sustainability in world fisheries. Nature 418(6898):689-695

Peters RG, Covello VT, McCallum DB (1997) The determinants of trust and credibility in environmental risk communication: an empirical study. Risk Anal 17(1):43-54

Petts J, Leach B (2000) Evaluating methods for public participation. R\&D Technical Report E135. Environment Agency, Bristol

PIRSA (2004) http://www.pir.sa.gov.au/pages/aquaculture/about_aqua_intro/about_aquaculture.htm, accessed 01/01/05

POT (Parliamentary Office of Technology) (2001) Open channels: public dialogue in science and technology. Report No. 153. House of Commons, London

Prime Mininster's Science, Engineering, Innovation Council (2002) Sustainable aquaculture. Commonwealth of Australia, Canberra

Productivity Commission (2004) Assessing environmental regulatory arrangements for aquaculture. Productivity Commission, Canberra

Shindler B, Wilton J, Wright A (2002a) A social assessment of ecosystem health public perspectives on pacific northwest forests. Department of Forest Resources, Oregon State University, Corvallis, Oregon

Shindler BA, Brunson M, Stankey GH (2002b) Social acceptability of forest conditions and management practices: a problem analysis. United States Department of Agriculture, Forest Service, Corvallis, Oregon

Slovic P (1999) Trust, emotion, sex, politics, and science: surveying the risk-assessment battlefield. Risk Anal 19(4):689-701

Stead SM, Burnell G, Goulletquer P (2002) Aquaculture and its role in integrated coastal zone management. Aquac Int 10(6):447-468

Swaffield S (1998) Frames of reference: a metaphor for analysing and interpreting attitudes of environmental policy makers and policy influencers. Environ Manage 22(4):495-504 
Tarrant MA, Cordell HK, Green GT (2003) PVF: a scale to measure public values of forests. J Forestry 101(6):24-30

Trettin L, Musham C (2000) Is trust a realistic goal of environmental risk communication. Environ Behav 32(3):410-427

Varadi L, Szucs I, Pekar F, Blokhin S, Csavas I (2001) Aquaculture development trends in Europe. In Subasinghe RP, Bueno P, Phillips MJ, Hough C, McGladdery SE, Arthur JR (eds) Aquaculture in the third millennium: technical proceedings of the conference on aquaculture in the third millennium. FAO, Bangkok and Rome, pp 397-416

Wilson D (2001) Community consultation survey of aquaculture developments in the bowen region. Queensland Department of State Development, Brisbane 